\title{
A phase II study of modified FOLFOX as first-line chemotherapy for metastatic gastric cancer in elderly patients with associated diseases
}

\author{
Vincenzo Catalano • Renato Bisonni - Francesco Graziano • Paolo Giordani • \\ Paolo Alessandroni - Anna Maria Baldelli - Virginia Casadei - David Rossi • \\ Stefano Luzi Fedeli · Silvia D'Emidio · Lucio Giustini · Giammaria Fiorentini
}

Received: 17 July 2012/Accepted: 23 September 2012/Published online: 11 October 2012

(C) The International Gastric Cancer Association and The Japanese Gastric Cancer Association 2012

\begin{abstract}
Background Elderly patients are generally underrepresented in the study populations of combination chemotherapy trials. This study evaluates the efficacy and safety of a modified FOLFOX regimen in elderly patients with metastatic gastric cancer and presenting associated disease(s).

Methods A total of 43 patients aged $\geq 70$ years received oxaliplatin $85 \mathrm{mg} / \mathrm{m}^{2}$ together with $6 \mathrm{~S}$-leucovorin $200 \mathrm{mg} / \mathrm{m}^{2}$ on day 1 , followed by a $46-\mathrm{h}$ infusion of 5 -fluorouracil $2,400 \mathrm{mg} / \mathrm{m}^{2}$, every 2 weeks. Assessment of response was performed every four cycles according to RECIST criteria.

Results Median patient age was 74 years (range, 70-83 years). Overall response rate was $34.9 \%$ [95\% confidence interval (CI), 20.6-49.1, with 3 complete responses and 12 partial responses. Grade 3 neutropenia occurred in 4 patients $(9.3 \%)$, fatigue in 3 patients $(7.0 \%)$, and vomiting in 2 patients $(4.6 \%)$. Grade 2 and 3 peripheral neuropathy was observed in 5 patients $(11.6 \%)$ and 1 patient $(2.3 \%)$, respectively. No treatment-related death was observed. Median progression-free and overall survival were 6.8 and 10.5 months, respectively.

Conclusions This modified FOLFOX regimen is an active and well-tolerated treatment for elderly patients with
\end{abstract}

V. Catalano $(\bowtie) \cdot$ F. Graziano · P. Giordani · P. Alessandroni ·

A. M. Baldelli · V. Casadei - D. Rossi - S. L. Fedeli .

S. D'Emidio - G. Fiorentini

U.O.C. Oncologia, Azienda Ospedaliera “Ospedali Riuniti

Marche Nord," Presidio San Salvatore, Via Lombroso,

61122 Pesaro, Italy

e-mail: catalano_v@yahoo.it

R. Bisonni · L. Giustini

Oncologia Medica, Ospedale di Fermo,

Via A. Murri, 63900 Fermo (FM), Italy metastatic gastric cancer and also represents a good therapeutic option in patients with associated disease(s).

Keywords Elderly - Palliative chemotherapy ·

Oxaliplatin $\cdot$ Metastatic gastric cancer

\section{Introduction}

Despite improvements in the early detection of gastric cancer, this disease remains one of the leading causes of cancer-related death worldwide [1]. A significant proportion of patients have inoperable stages at the time of diagnosis, when systemic chemotherapy is indicated with the aim of palliation. In Western countries, regimens containing 5-fluorouracil (5-FU) and cisplatin remain an accepted standard [2]. The addition of a third drug, basically epirubicin or docetaxel, may be helpful, even if it translates into only a small benefit in terms of overall survival $[3,4]$. However, when adding a third drug to a double combination, toxicity may significantly increase, and this aspect should be taken into account when considering triple drug combinations for frail and elderly patients.

The definition of an elderly patient varies according to social and economic situations. However, in most developed and developing countries, 65 or 70 years of age is a commonly used limit because of the decreased role of the subject in the community and society. Although the majority of gastric cancer patients are elderly, patients older than 65-70 years have been often excluded from, or underrepresented in, the study populations of combination chemotherapy trials [5, 6]. Elderly patients may have a functional fall of reserve capacity and may show high incidence of comorbidity. In prospective trials, the 
eligibility criteria are quite stringent, and a low proportion of 70-year-old patients is enrolled. For these reasons, results from the published literature are not fully transferable to the elderly population. Consequently, there is uncertainty about the type and the extent of systemic palliative chemotherapy that should be offered to elderly patients with gastric cancer.

In gastric cancer patients, oxaliplatin has shown a more favorable toxicity profile than cisplatin [4, 7]. Furthermore, a combination chemotherapy of 5-FU with oxaliplatin, mainly FOLFOX regimens, has been investigated in numerous phase II studies, using different doses and schedules [8-12], and has shown considerable antitumor activity. Insofar as toxicity is concerned, significant toxicities, including myelosuppression and peripheral neuropathy, are a major issue for elderly patients. When compared to standard FOLFOX schedules, both weekly and biweekly reduced-dose combinations of oxaliplatin/5FU without 5-FU bolus showed a more favorable toxicity profile with lower rates of peripheral neuropathy and myelosuppression $[9,10,12]$.

During the past decades, various studies [13-17] have assessed the role of combination chemotherapy containing oxaliplatin and 5-FU for elderly patients with advanced gastric cancer. However, in this setting little attention was paid to the presence of comorbidities of elderly patients.

Considering that the aim of treatment in metastatic gastric cancer is palliation, great importance should be given to the tolerability of treatment, and this issue is of particular interest especially if we consider elderly patients. The aim of this study was to examine the efficacy and toxicity of a modified FOLFOX regimen as first-line chemotherapy for elderly patients (aged 70 years or more) with metastatic gastric cancer and suffering from associated disease(s).

\section{Methods}

\section{Eligibility}

Elderly patients (aged $\geq 70$ years) with histologically confirmed, relapsed, or metastatic adenocarcinoma of the stomach, or of the gastroesophageal junction, were eligible if they met the following criteria: Eastern Cooperative Oncology Group (ECOG) performance status 0-2; measurable disease according to Response Evaluation Criteria in Solid Tumors (RECIST); adequate liver [serum bilirubin $\leq 2.0 \times$ upper normal limit (UNL); serum aspartate aminotransferase (AST) and alanine aminotransferase (ALT) $\leq 2.5 \times \mathrm{UNL}$, or $<5 \times \mathrm{UNL}$ for patients with liver metastases; serum alkaline phosphatase $\leq 5.0 \times \mathrm{UNL}]$, renal (serum creatinine $\leq 1.5 \mathrm{mg} / \mathrm{dl}$ or calculated creatinine clearance by Cockcroft-Gault equation $>40 \mathrm{ml} / \mathrm{min}$ ), and bone marrow [absolute neutrophil count (ANC) $\geq 1,500 /$ $\mathrm{mm}^{3}$, platelet count $\geq 100,000 / \mathrm{mm}^{3}$ ] functions; estimated life expectancy $\geq 3$ months. Patients were excluded if they had only sites of disease previously treated with radiotherapy or had had prior chemotherapy for metastatic disease, except adjuvant chemotherapy completed at least 12 months before enrollment, previous treatment with oxaliplatin, brain metastases, significant gastrointestinal bleeding, peripheral neuropathy $\geq$ grade 2 , serious uncontrolled concomitant disease, other primary malignancy (except squamous or basal cell skin cancer or cervical carcinoma in situ) within the last 5 years, or were unable to comply with the requirements of the protocol. In addition to the activities of daily living (ADL) and instrumental activities of daily living (IADL) scales [18], the comprehensive geriatric assessment (CGA) was used at study entry to identify and exclude frail elderly patients [19]. The protocol was approved by a local institutional review board, and written informed consent was obtained from all participants.

\section{Study design and dose modifications}

Oxaliplatin $85 \mathrm{mg} / \mathrm{m}^{2}$ and S-leucovorin $200 \mathrm{mg} / \mathrm{m}^{2}$ were given as a 2-h intravenous infusion followed by 5-FU $2,400 \mathrm{mg} / \mathrm{m}^{2}$ as a $46-\mathrm{h}$ continuous infusion. The use of central venous catheters and disposable pumps allowed chemotherapy administration on an outpatient basis. The cycles were repeated every 2 weeks and treatment was continued until disease progression, unacceptable toxicity, patient refusal, or the decision of the patient's physician to terminate treatment. The administration of glutathione was allowed for prevention of oxaliplatin-induced neuropathy. Antiemetic prophylaxis was given according to local protocols. According to treatment policy at each participating institution, the use of growth factors for white cells [granulocyte colony-stimulating factor (G-CSF)] and erythropoietin was allowed in the case of acute toxicity.

Dose modifications were performed on the basis of toxicity. Chemotherapy was delayed for up to 14 days when neutrophil count was $<1,500 / \mathrm{mm}^{3}$ and/or platelet count was $<100,000 / \mathrm{mm}^{3}$. In the case of toxicity of grade 2 or greater, except in the case of alopecia, chemotherapy was delayed 1 week, and then restarted after full recovery. Reduction of $20 \%$ in the dosage of all drugs was applied for grade 3 nonhematological toxicity, for grade 4 hematological toxicity, for febrile neutropenia, or for recurrent grade 3 thrombocytopenia and/or neutropenia in the previous cycle. For grade 3 or 4 gastrointestinal toxicities or grade 3 hand-foot syndrome, 5-FU was reduced by $20 \%$. For grade 2 cardiotoxicity, 5-FU treatment was discontinued. Patients with unsolved toxicity of grade 2 or greater after two consecutive treatment delays, or experiencing 
grade 4 nonhematological toxicity, except alopecia, went off the study.

In cases of sensorial neuropathy accompanied by pain lasting longer than 7 days, oxaliplatin was reduced by $20 \%$. If peripheral neuropathy persisted between the two following cycles, the oxaliplatin dose in the next cycle had to be reduced by $50 \%$. Treatment withdrawal was planned in cases of grade 3 neuropathy.

Response and toxicity assessment

In addition to a full medical history and physical examination, baseline assessments included complete blood counts, chemistries, urinalysis, and electrocardiography before starting, ECOG performance status, computed tomography (CT) of the abdomen and pelvis, and chest X-ray or CT scan. ADL and IADL scales and the CGA were calculated before enrollment in the study. Other investigations, for example, bone scan or bone X-ray, or a magnetic resonance imaging (MRI) scan of some sites of disease, were performed, if clinically indicated, to document metastatic disease. The baseline assessment of disease was carried out within 4 weeks before the start of the treatment. Full medical history and physical examination including ECOG performance status and blood chemistries were assessed before each treatment cycle. Responses were classified according to RECIST criteria for every four cycles of modified FOLFOX. Responses were confirmed by subsequent CT scans every 4-6 weeks after the initial response documentation. All eligible patients were included in the response and survival analysis on an 'intent-to-treat' basis.

Toxicity was graded using the National Cancer Institute Common Terminology Criteria for Adverse Events (NCICTCAE), version 3.0.

\section{Statistical analysis}

This was a multicenter phase II study. The primary endpoint was the cumulative objective response rate of the planned modified FOLFOX. Secondary endpoints were toxicity, progression-free survival (PFS), and overall survival (OS). The optimal two-stage phase II design was adopted for this phase II trial. The treatment program was designed to reject an overall response rate for the modified FOLFOX regimen of less than $20 \%$ (p0) and to provide a statistical power of $80 \%$ in assessing the activity of the regimen (in terms of response rate) as $40 \%$ (p1). Early discontinuation of the study was provided for in the case of fewer than three responses in the first 13 assessable patients treated with modified FOLFOX ( $\alpha$ and $\beta$ error probabilities, 0.05 and 0.02 , respectively). Otherwise, more than 12 responses from among a total of 43 patients are required to consider this regimen as acceptable for elderly patients with metastatic gastric cancer. PFS was measured from the onset of chemotherapy to the date of progression (per investigator assessment), or death from any cause. OS was calculated from the onset of chemotherapy until death or until the censoring date for follow-up (31 December 2010). Patient survival was examined using the Kaplan-Meier product limit method.

\section{Results}

Forty-three patients were enrolled from two institutions (Pesaro and Fermo). The characteristics of the patients are summarized in Table 1. Median patient age was 74 years

Table 1 Patient characteristics

\begin{tabular}{|c|c|c|}
\hline Characteristics & $n$ & $\%$ \\
\hline Number of patients & 43 & \\
\hline Sex, male/female & $27 / 16$ & $62.8 / 37.2$ \\
\hline Age, years median (range) & $74(70-83)$ & \\
\hline \multicolumn{3}{|l|}{ Performance status } \\
\hline 0 & 19 & 44.2 \\
\hline 1 & 20 & 46.5 \\
\hline 2 & 4 & 9.3 \\
\hline \multicolumn{3}{|l|}{ Lauren classification } \\
\hline Intestinal type & 23 & 53.5 \\
\hline Diffuse type & 16 & 37.2 \\
\hline Mixed & 4 & 9.3 \\
\hline \multicolumn{3}{|l|}{ Primary tumour } \\
\hline Oesophagogastric junction & 9 & 20.9 \\
\hline Stomach & 32 & 74.4 \\
\hline Anastomosis & 2 & 4.7 \\
\hline \multicolumn{3}{|l|}{ Prior therapy } \\
\hline Surgery & 26 & 60.5 \\
\hline Adjuvant chemotherapy & 6 & 14.0 \\
\hline \multicolumn{3}{|l|}{ Number of organs involved } \\
\hline 1 & 10 & 23.3 \\
\hline 2 & 20 & 46.5 \\
\hline $3-5$ & 13 & 30.2 \\
\hline \multicolumn{3}{|l|}{ Metastatic sites } \\
\hline Lymph nodes & 17 & 39.5 \\
\hline Liver & 13 & 30.2 \\
\hline Peritoneum & 18 & 41.9 \\
\hline Bone & 1 & 2.3 \\
\hline Lung & 6 & 13.9 \\
\hline Other & 10 & 23.2 \\
\hline \multicolumn{3}{|c|}{ Royal Marsden Hospital Prognostic Index } \\
\hline Good & 11 & 25.6 \\
\hline Moderate & 30 & 69.8 \\
\hline Poor & 2 & 4.6 \\
\hline
\end{tabular}


Table 2 Pretreatment classification of comorbidity

\begin{tabular}{lrr}
\hline Associated disease & $n$ & $\%$ \\
\hline Hypertension $^{2}$ & 30 & 69.8 \\
Cardiac disease $^{\mathrm{a}}$ & 14 & 32.6 \\
Respiratory disease $^{\mathrm{b}}$ & 5 & 11.6 \\
Diabetes mellitus $^{\text {Liver disease }}{ }^{\mathrm{c}}$ & 9 & 20.9 \\
Neurological disease $^{\mathrm{d}}$ & 2 & 4.6 \\
Renal disease $^{\mathrm{e}}$ & 5 & 11.6 \\
Others $^{\mathrm{f}}$ & 5 & 11.6 \\
Number of associated disease(s) & 5 & 11.6 \\
1 & 19 & 44.2 \\
2 & 15 & 34.9 \\
3 & 9 & 20.9 \\
\hline
\end{tabular}

${ }^{a}$ Arrhythmia, valvular heart disease, coronary heart disease, myocardial infarct

b Emphysema, asthma, chronic obstructive pulmonary disease

${ }^{c}$ Liver cirrhosis, chronic hepatitis $\mathrm{C}$

${ }^{\mathrm{d}}$ Cerebral infarct disease

e Chronic renal insufficiency, kidney polycystosis

${ }^{\mathrm{f}}$ Rheumatoid arthritis, hypothyroidism, obesity, ulcerative colitis

(range, 70-83 years).Twenty-seven patients (62.8\%) were men, and 39 patients $(90.9 \%)$ had an ECOG performance status of $0-1$. Metastases were primarily in the peritoneum $(41.9 \%)$, lymph nodes $(39.5 \%)$, and liver $(30.2 \%)$. At least two organs were involved in nearly $75 \%$ of patients. All except 2 patients had a good to moderate Royal Marsden Hospital (RMH) Prognostic Index [20]. All patients had comorbidities with a median number of associated diseases of 2 (range, 1-3) (Table 2). Hypertension and cardiac disease were the most frequent associated diseases.

\section{Response evaluation}

Among the 43 patients who received chemotherapy, the tumor response was evaluable according to the RECIST criteria in 41 patients. Two patients died after the second cycle of chemotherapy: 1 patient of myocardial infarction, and the other of cerebrovascular disease, occurring 10 and 12 days, respectively, from the date of the second cycle, without showing signs of toxicity or early progression. After the modified FOLFOX regimen, 3 patients achieved complete response, 12 patients showed partial response, 15 patients had stable disease, and 11 patients progressed, with an overall response rate of $34.9 \%(95 \% \mathrm{CI}$, 20.6-49.1) (Table 3). The 3 patients reporting a complete response were free from progression at $20,23+$, and $55+$ months, respectively, and alive as of 31 December 2010.
Table 3 Objective tumor response rates in advanced untreated elderly gastric cancer patients $(n=43)$, according to RECIST

\begin{tabular}{lc}
\hline Response & Number $(\%)$ \\
\hline Complete response & $3(7.0)$ \\
Partial response & $12(27.9)$ \\
ORR (95 \% CI) & $34.9(20.6-49.1)$ \\
Stable disease & $15(34.9)$ \\
Progressive disease & $11(25.6)$ \\
Not assessable & $2(4.6)$ \\
\hline CI confidence interval, ORR overall response rate, & RECIST Response \\
Evaluation Criteria in Solid Tumors
\end{tabular}

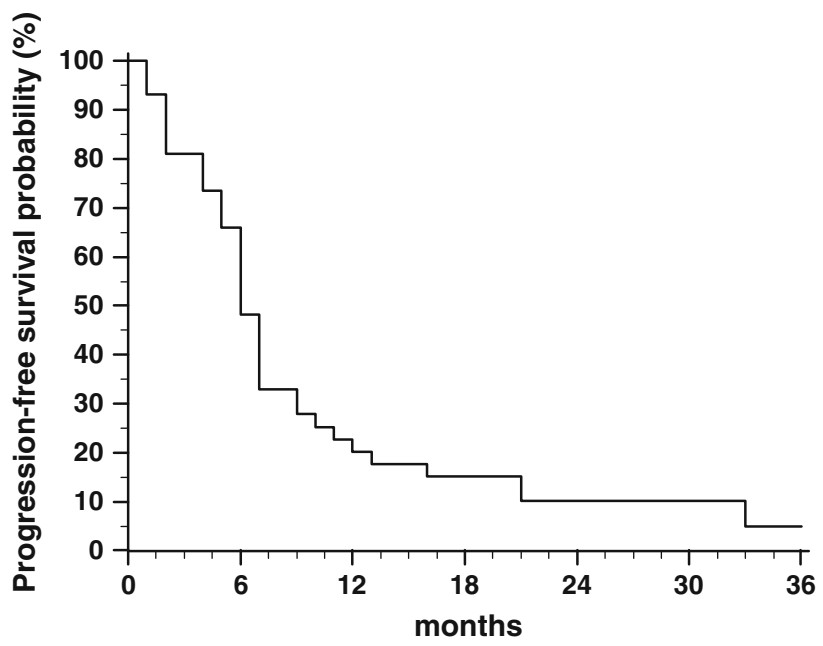

Fig. 1 Kaplan-Meier curve of progression-free survival $(n=43)$

Survival analysis

Forty-three patients were included in the survival analysis on an intention-to-treat basis. After a median follow-up of 38 months, PFS was 6.8 (range, 1-55+) months (Fig. 1) and OS was 10.5 (range, 1-55+) months (Fig. 2), with $46.1 \%$ of patients alive at 1 year. Second-line chemotherapy was administered to 14 patients (32.6\%): 10 patients received FOLFIRI; and 1 patient received irinotecan plus capecitabine, paclitaxel, docetaxel, or irinotecan alone.

\section{Treatment administration}

A total of 324 cycles were administered, with a median of 8 cycles (range, 1-15 cycles) for patients. Of 43 patients, 29 $(67.4 \%)$ received at least 6 cycles, 25 patients $(58.1 \%)$ received at least 8 cycles, and 13 patients (30.2\%) received at least 10 cycles. The relative dose intensities of oxaliplatin and 5-FU were $90.8 \%$ and $91.3 \%$, respectively. The median cumulative dose of oxaliplatin was 




Fig. 2 Kaplan-Meier curve of overall survival $(n=43)$

$612 \mathrm{mg} / \mathrm{m}^{2}$ (range, $85-1,262$ ) and that of $5-\mathrm{FU}$ was $17,280 \mathrm{mg} / \mathrm{m}^{2}(2,400-35,640)$.

Twenty-two of the $324(6.8 \%)$ cycle intervals were delayed in 14 patients $(32.6 \%)$. Most cycle delays were caused by neutropenia and thrombocytopenia. Twentyfive patients $(58.1 \%)$ had at least one dose reduction in a total of 119 cycles $(36.7 \%)$. The main reason for discontinuing study treatment was disease progression. Other reasons included death (4 patients) and refusal (1 patient). Only 1 patient was taken off the study treatment because of grade 3 neurotoxicity after receiving 15 cycles of chemotherapy.

\section{Toxicity}

The toxicity profile of the modified FOLFOX regimen was acceptable (Table 4). The incidence of severe adverse events was very low and no grade 4 toxicity was observed. The most common toxicities were hematological. NCICTCAE grade 3 neutropenia and anemia were recorded in $9.3 \%$ and $2.3 \%$ of cases, respectively. Grade 1-2 anemia, thrombocytopenia, and neutropenia occurred in $51.2 \%$, $23.2 \%$, and $23.2 \%$ of patients, respectively. No patient experienced febrile neutropenia. Among nonhematological toxicities, fatigue was frequently reported $(39.5 \%)$, but it was of grade 3 only in $2(7.0 \%)$ patients. Other toxicities were generally mild (Table 4). As expected, peripheral neuropathy was observed in $41.9 \%$ of the population and was graded as severe (grade 3$)$ in $1(2.3 \%)$ patient, who received a cumulative dose of oxaliplatin of $1,020 \mathrm{mg} / \mathrm{m}^{2}$. The incidence of the peripheral neuropathy correlated with the cumulative dose of oxaliplatin, with 12 of 18 (66.6\%) patients reporting grade 1-3 toxicity and receiving a cumulative oxaliplatin dose $>600 \mathrm{mg} / \mathrm{m}^{2}$. There was no treatment-related mortality.
Table 4 Toxicity according to treatment (NCI-CTCAE)

\begin{tabular}{lclll}
\hline Grade & $n(\%)$ & & & \\
\cline { 2 - 5 } & 1 & 2 & 3 & 4 \\
\hline Neutropenia & $5(11.6)$ & $5(11.6)$ & $4(9.3)$ & 0 \\
Anemia & $18(41.9)$ & $4(9.3)$ & $1(2.3)$ & 0 \\
Thrombocytopenia & $6(13.9)$ & $4(9.3)$ & 0 & 0 \\
Nausea & $2(4.6)$ & $5(11.6)$ & 0 & 0 \\
Vomiting & $1(2.3)$ & $5(11.6)$ & $2(4.6)$ & 0 \\
Diarrhea & $5(11.6)$ & $5(11.6)$ & $1(2.3)$ & 0 \\
Stomatitis & 0 & $1(2.3)$ & 0 & 0 \\
Fatigue & $6(13.9)$ & $8(18.6)$ & $3(7.0)$ & 0 \\
Anorexia & $3(7.0)$ & $3(7.0)$ & $1(2.3)$ & 0 \\
Neurological & $12(27.9)$ & $5(11.6)$ & $1(2.3)$ & 0 \\
Others & $1(2.3)$ & $7(16.3)$ & 0 & 0 \\
\hline
\end{tabular}

NCI-CTCAE National Cancer Institute Common Terminology Criteria for Adverse Events

\section{Discussion}

Although the number of deaths from gastric cancer has declined during the past, a large proportion of elderly patients are primarily affected by the disease. SEER data from the United States showed that $65.5 \%$ of patients with gastric cancers are diagnosed when older than 65 years: the median age at diagnosis of such patients was 71 years, and the median age of gastric cancer-related death was 74 years [6]. Elderly cancer patients often suffer multiple comorbidities, take many medications, and have age-associated physiological problems, such as impaired organ function and functional changes, that make the selection of optimal treatment difficult $[21,22]$. This aspect is also hampered by the underrepresentation of older patients in cancer clinical trials. Overall, from 1997 to 2000, only $32 \%$ of participants in phase II and III trials sponsored by the National Cancer Institute were elderly, compared with $61 \%$ of new cancer cases who are elderly [23]. Age is a significant barrier to recruitment. Chronological age alone is not a sufficient reason to withhold palliative treatment from an elderly gastric cancer patient. Elderly patients who fulfill the inclusion criteria of clinical trials could experience the same advantages and toxicities from chemotherapy as younger patients. In contrast to physicians' perceptions, older patients do not recognize their age as an important issue for refusing trials [24]. Furthermore, performance status is not helpful to estimate the general condition of elderly patients, and other factors regarding their functional, social, and mental status should be considered [25].

In a recently published meta-analysis, Wagner et al. [26] concluded that further research on the risks and benefits of palliative chemotherapy in elderly gastric cancer patients is necessary before applying a recommendation for this group 
of patients. In fact, they observed that the median age in the participants included in various trials [26] was well below the median age (64-65 years) reported in some trials $[4,7]$.

There is a lack of prospective studies directly comparing the outcomes and the tolerability of chemotherapy in young and elderly patients, although some data are available in gastric cancer from a retrospective analysis [27]. Trumper et al. [27] evaluated retrospectively 1,080 patients who were enrolled into three randomized controlled trials assessing 5-FU-based combination chemotherapy. They found that elderly patients obtained similar benefits from palliative chemotherapy in terms of symptomatic response, tumor regression, and survival, without increased toxicities.

One may suggest that elderly patients without significant comorbidities should be treated with the same regimens as younger patients with advanced gastric cancer. However, extrapolation of the results from retrospective reviews or meta-analyses to elderly patients should be done with caution. It is strongly suggested that specific clinical trials limited to older patients should be planned to evaluate response, benefit treatment tolerability, and the effect of comorbid conditions, so that clinicians may optimize their treatment of older cancer patients.

For the palliative treatment of metastatic gastric cancer, a doublet containing oxaliplatin and fluoropyrimidines could be considered as an option. Results from a prospective randomized trial showed the non-inferiority of oxaliplatin, as compared to cisplatin, in the treatment of advanced gastric cancer, while decreasing toxicity [4]. Of interest, a subgroup analysis from a phase III randomized trial [7] reported significantly better results for elderly patients treated with oxaliplatin as compared to cisplatin. In this trial, patients with advanced gastric cancer were randomized to receive a 5-FU-based regimen with cisplatin (FLP regimen) or oxaliplatin (FLO regimen). The primary endpoint of the study, PFS, was unmet. However, in the subgroup of patients older than 65 years, the FLO regimen achieved improved efficacy in terms of response rate, PFS, and OS as compared with the FLP regimen [7]. In a subsequent randomized study on elderly gastric cancer patients, the FLO regimen has formed the basis for the addition of a third drug, docetaxel (FLOT regimen) [17]. The FLOT regimen improved efficacy with manageable toxicity compared with the FLO chemotherapy.

This trial aimed to assess a chemotherapy regimen in elderly patients who had associated disease(s). We used a modified FOLFOX regimen with the omission of bolus 5-FU with the aim to improve tolerability of such regimen in the elderly population, while preserving the outcome. This strategy was adopted based on the results of previous [9] and ongoing studies [13-16] of oxaliplatin/5-FU combination regimens. The population consisted of patients with a median age of 74 years, which is among the highest reported in this setting. The overall response rate was $34.9 \%$, which compares favorably with other phase II studies of FOLFOX chemotherapy, ranging from $32.2 \%$ to $52.5 \%[13-16,28]$ (see Table 5). This overall response rate is noteworthy if we consider that all the patients had metastatic or recurrent gastric cancer compared with other studies in which a variable percentage (from $8 \%$ to $35 \%$ ) of enrolled patients had locally advanced disease $[8,11,14$, $15,17,28]$. In our study we omitted the 5 -FU bolus injection to reduce myelosuppression. This modified FOLFOX regimen showed a $9.3 \%$ occurrence of grade 3-4 neutropenia, which is lower than the $36-38 \%$ shown with the FOLFOX-4 and FOLFOX-6 regimens $[8,11]$.

The dose of oxaliplatin was $85 \mathrm{mg} / \mathrm{m}^{2}$, every 2 weeks, to avoid an increased incidence of peripheral sensory neuropathy associated with higher doses of oxaliplatin [8], which could be an important issue especially for elderly patients with associated disease (e.g., diabetes). In the present series, no grade 4 peripheral sensory neuropathy occurred, whereas grade 2-3 neurotoxicity was reported in $13.9 \%$ of cases. Only 1 patient experienced grade 3 neuropathy, a proportion similar to that of the original FOLFOX-4 [11] or of other modified FOLFOX regimens used in elderly patients employing an $85 \mathrm{mg} / \mathrm{m}^{2}$ dose of oxaliplatin [14-16], but lower than that reported by Louvet et al. [8] with the FOLFOX-6 regimen (grade 3 neurotoxicity in $21 \%$ of cases) (Table 5). However, in our study the median cumulative dose of $612 \mathrm{mg} / \mathrm{m}^{2}$ for oxaliplatin is lower than in the original FOLFOX-6, in which a dose of oxaliplatin of $100 \mathrm{mg} / \mathrm{m}^{2}$ was used with a median cumulative dose of $901 \mathrm{mg} / \mathrm{m}^{2}$ for oxaliplatin.

Together with the omission of bolus 5-FU and the oxaliplatin dose, the use of $5-\mathrm{FU}$ at $2,400 \mathrm{mg} / \mathrm{m}^{2}$ continuous infusion in $46 \mathrm{~h}$ seems tolerable. We observed no grade 4 toxicities, whereas grade 1-3 gastrointestinal toxicities were reported in a moderate number of patients (Tables 4, 5). Moreover, the dose intensities of oxaliplatin and 5-FU were nearly $90 \%$ of those pre-planned, thus verifying the tolerability of this regimen. These results indicate that a modified FOLFOX regimen of $85 \mathrm{mg} / \mathrm{m}^{2}$ oxaliplatin could be considered an option for elderly patients with unresectable or recurrent gastric cancer and with associated comorbidities.

In elderly gastric cancer patients, different trials have assessed palliative chemotherapy regimens, including fluoropyrimidines with oxaliplatin (see Table 5) or irinotecan [29], but large-scale trials are lacking. For this reason, in this subset of patients there is uncertainty about the use of systemic palliative chemotherapy. It is crucial to select palliative treatments that are active, but at the same time these treatments need to be sufficiently tolerable. Hematological toxicity, cardiotoxicity, neurotoxicity, renal 
Table 5 Comparison with previous FOLFOX regimens in gastric cancer

\begin{tabular}{|c|c|c|c|c|c|c|c|c|}
\hline $\begin{array}{l}\text { Author, year } \\
\text { [Ref. number] }\end{array}$ & $n$ & $\begin{array}{l}\text { Regimen (dose oxa/ } \\
\text { 5-FUb/5-FUi.c.) }\end{array}$ & $\begin{array}{l}\text { Median } \\
\text { age } \\
\text { (range) } \\
\text { (years) }\end{array}$ & $\begin{array}{l}\text { ORR } \\
(\%)\end{array}$ & $\begin{array}{l}\text { PFS } \\
\text { (months) }\end{array}$ & $\begin{array}{l}\text { OS } \\
\text { (months) }\end{array}$ & $\begin{array}{l}\text { Toxicity } \\
\text { G1-2 (\%) }\end{array}$ & $\begin{array}{l}\text { Toxicity } \\
\text { G3-4 (\%) }\end{array}$ \\
\hline \multicolumn{9}{|l|}{ All ages } \\
\hline Louvet, 2002 [8] & 54 & $\begin{array}{l}\text { mFOLFOX } \\
(100 / 400 / 3000)\end{array}$ & $61(31-75)$ & 44.9 & 6.2 & 8.6 & $\begin{array}{l}\text { Anemia (80) } \\
\text { Thrombocytopenia } \\
\quad(68) \\
\text { Neurotoxicity (66) } \\
\text { Neutropenia (30) } \\
\text { Nausea (68) } \\
\text { Asthenia (55) }\end{array}$ & $\begin{array}{l}\text { Neutropenia (38) } \\
\text { Neurotoxicity (21) } \\
\text { Anemia (11) } \\
\text { Nausea (6) }\end{array}$ \\
\hline \multirow[t]{4}{*}{$\begin{array}{l}\text { De Vita, } 2005 \\
{[11]}\end{array}$} & 61 & FOLFOX-4 & $64(47-75)$ & 38.0 & 7.1 & 11.2 & Anemia (37) & Neutropenia (36) \\
\hline & & & & & & & $\begin{array}{l}\text { Thrombocytopenia } \\
\text { (32) }\end{array}$ & Anemia (10) \\
\hline & & & & & & & Neurotoxicity (26) & Diarrhea (10) \\
\hline & & & & & & & $\begin{array}{l}\text { Neutropenia (23) } \\
\text { Diarrhea (23) } \\
\text { Nausea (21) }\end{array}$ & Neurotoxicity (5) \\
\hline \multirow[t]{4}{*}{$\begin{array}{l}\text { Cavanna, } 2006 \\
{[28]}\end{array}$} & 56 & FOLFOX-4 & $65(28-78)$ & 42.9 & 6.2 & 8.6 & Nausea (69) & Neutropenia (20) \\
\hline & & & & & & & Vomiting (39) & Anemia (11) \\
\hline & & & & & & & Anorexia (39) & $\begin{array}{l}\text { Thrombocytopenia } \\
\text { (7) }\end{array}$ \\
\hline & & & & & & & $\begin{array}{l}\text { Diarrhea (33) } \\
\text { Neurotoxicity (34) } \\
\text { Neutropenia (25) }\end{array}$ & Neurotoxicity (5) \\
\hline \multicolumn{9}{|l|}{ Elderly population } \\
\hline Choi, 2007 [13] & 37 & $\begin{array}{l}\text { mFOLFOX } \\
(100 /-/ 2400)\end{array}$ & $72(67-79)$ & 41.2 & 5.7 & 9.8 & $\begin{array}{l}\text { Anemia (54) } \\
\text { Nausea (73) } \\
\text { Neurotoxicity (35) } \\
\text { Neutropenia (24) } \\
\text { Vomiting (35) } \\
\text { Diarrhea (19) }\end{array}$ & $\begin{array}{l}\text { Neutropenia (8) } \\
\text { Anemia (3) }\end{array}$ \\
\hline Nardi, 2007 [14] & 33 & FOLFOX-4 & $74(66-79)$ & 32.2 & 6.4 & NR & $\begin{array}{l}\text { Nausea (77) } \\
\text { Vomiting (61) } \\
\text { Diarrhea (51) } \\
\text { Neutropenia (48) } \\
\text { Neurotoxicity (45) } \\
\text { Anemia (35) }\end{array}$ & $\begin{array}{l}\text { Neutropenia (19) } \\
\text { Anemia (10) } \\
\text { Vomiting (6) }\end{array}$ \\
\hline \multirow[t]{2}{*}{ Liu, 2008 [15] } & 44 & $\begin{array}{l}\text { mFOLFOX (85/-/ } \\
2000)\end{array}$ & $69(65-83)$ & 52.5 & 6.5 & 10.0 & Nausea/vomiting (43) & Neutropenia (7) \\
\hline & & & & & & & $\begin{array}{l}\text { Neurotoxicity (41) } \\
\text { Diarrhea (32) } \\
\text { Stomatitis (27) } \\
\text { Neutropenia (16) }\end{array}$ & $\begin{array}{l}\text { Diarrhea (7) } \\
\text { Neurotoxicity (2) }\end{array}$ \\
\hline \multirow[t]{6}{*}{ Present study } & 43 & $\begin{array}{l}\text { mFOLFOX (85/-I } \\
2400)\end{array}$ & $74(70-83)$ & 34.9 & 6.8 & 10.5 & Anemia (51) & Neutropenia (9) \\
\hline & & & & & & & Neurotoxicity (39) & Fatigue (7) \\
\hline & & & & & & & Fatigue (32) & Vomiting (5) \\
\hline & & & & & & & Neutropenia (23) & Neurotoxicity (2) \\
\hline & & & & & & & $\begin{array}{l}\text { Thrombocytopenia } \\
\text { (23) }\end{array}$ & \\
\hline & & & & & & & Diarrhea (23) & \\
\hline
\end{tabular}

${ }^{a}$ FOLFOX-4 refers to the classical schedule; mFOLFOX refers to the modification of FOLFOX regimen (dosage of drugs is provided in brackets)

5-FUb 5-fluorouracil bolus, 5-FUi.c. 5-fluorouracil continuous infusion, med median, ORR overall response rate, oxa oxaliplatin, OS overall survival, $P F S$ progression-free survival 
toxicity, mucositis, and diarrhea should be minimized to preserve a good state of health and quality of life. The presence of comorbidities may preclude the use of drugs such as anthracyclines, cisplatin, docetaxel, or oxaliplatin for elderly gastric cancer patients, and data on these drugs in patients with comorbidities are lacking for reasons of the underrepresentation of such groups in prospective studies. Quality of life is another issue that deserves evaluation, as it could be impaired as the intensity of chemotherapy increases, and until now this has not been studied sufficiently.

Data from this trial are of some value considering that the overall response rate, PFS, and OS are in the range of other trials and that toxicity was restrained.

Standard treatment for metastatic gastric cancer in elderly patients should not be extrapolated from large retrospective subset analyses or from small phase II prospective trials. The results of this study demonstrate that, in advanced gastric cancer, a regimen consisting of a dose of $85 \mathrm{mg} / \mathrm{m}^{2}$ oxaliplatin combined with leucovorin plus continuous infusion 5-FU, but omitting the administration of bolus 5-FU, is effective as a first-line treatment and has an acceptable toxicity profile in elderly patients, also presenting with associated disease. Further prospective randomized studies to determine the most effective and tolerable regimen in elderly patients with advanced gastric cancer are warranted.

Acknowledgments The authors thank Mrs. Sarah Helen Baulk for her improvements to the English in the manuscript.

Conflict of interest The authors declare no conflict of interest.

\section{References}

1. Parkin DM, Bray F, Ferlay J, Pisani P. Global cancer statistics, 2002. CA Cancer J Clin. 2005;55:74-108.

2. Catalano V, Labianca R, Beretta GD, Gatta G, de Braud F, Van Cutsem E. Gastric cancer. Crit Rev Oncol Hematol. 2009;71: 127-64.

3. Van Cutsem E, Moiseyenko VM, Tjulandin S, Majlis A, Constenla M, Boni C, et al. Phase III study of docetaxel and cisplatin plus fluorouracil compared with cisplatin and fluorouracil as firstline therapy for advanced gastric cancer: a report of the V325 Study Group. J Clin Oncol. 2006;24:4991-7.

4. Cunningham D, Starling N, Rao S, Iveson T, Nicolson M, Coxon $\mathrm{F}$, et al. Capecitabine and oxaliplatin for advanced esophagogastric cancer. N Engl J Med. 2008;358:36-46.

5. Talarico L, Chen G, Pazdur R. Enrollment of elderly patients in clinical trials for cancer drug registration: a 7-year experience by the US Food and Drug Administration. J Clin Oncol. 2004;22: 4626-31.

6. Ries LAG, Melbert D, Krapcho M, Mariotto A, Miller BA, Feuer EJ, et al. SEER Cancer Statistics Review, 1975-2004. National Cancer Institute: Bethesda. http://seer.cancer.gov/csr/1975_2004/ based on November 2006 SEER data submission, 2007.
7. Al Batran SE, Hartmann JT, Probst S, Schmalenberg H, Hollerbach S, Hofheinz R, et al. Phase III trial in metastatic gastroesophageal adenocarcinoma with fluorouracil, leucovorin plus either oxaliplatin or cisplatin: a study of the Arbeitsgemeinschaft Internistische Onkologie. J Clin Oncol 2008;26:1435-42.

8. Louvet C, André T, Tigaud JM, Gamelin E, Douillard JY, Brunet $\mathrm{R}$, et al. Phase II study of oxaliplatin, fluorouracil, and folinic acid in locally advanced or metastatic gastric cancer patients. J Clin Oncol. 2002;20:4543-8.

9. Al-Batran SE, Atmaca A, Hegewisch-Becker S, Jaeger D, Hahnfeld S, Rummel MJ, et al. Phase II trial of biweekly infusional fluorouracil, folinic acid, and oxaliplatin in patients with advanced gastric cancer. J Clin Oncol. 2004;22:658-63.

10. Chao Y, Yeh KH, Chang CJ, Chen LT, Chao TY, Wu MF, et al. Phase II study of weekly oxaliplatin and 24-h infusion of highdose 5-fluorouracil and folinic acid in the treatment of advanced gastric cancer. Br J Cancer. 2004;91:453-8.

11. De Vita F, Orditura M, Matano E, Bianco R, Carlomagno C, Infusino $\mathrm{S}$, et al. A phase II study of biweekly oxaliplatin plus infusional 5-fluorouracil and folinic acid (FOLFOX-4) as firstline treatment of advanced gastric cancer patients. $\mathrm{Br} \mathrm{J}$ Cancer. 2005;92:1644-9.

12. Lordick F, Lorenzen S, Stollfuss J, Vehling-Kaiser U, Kullmann F, Hentrich M, et al. Phase II study of weekly oxaliplatin plus infusional fluorouracil and folinic acid (FUFOX regimen) as firstline treatment in metastatic gastric cancer. Br J Cancer. 2005;93: $190-4$.

13. Choi IS, Oh D-Y, Kim B-S, Lee K-W, Kim JH, Lee J-S Oxaliplatin, 5-FU, folinic acid as first-line palliative chemotherapy in elderly patients with metastatic or recurrent gastric cancer. Cancer Res Treat. 2007;39:99-103.

14. Nardi M, Azzarello D, Maisano R, Del Medico P, Giannicola R, Raffaele M, et al. FOLFOX-4 regimen as fist-line chemotherapy in elderly patients with advanced gastric cancer: a safety study. J Chemother. 2007;19:85-9.

15. Liu ZF, Guo QS, Zhang XQ, Yang XG, Guan F, Fu Z, et al. Biweekly oxaliplatin in combination with continuous infusional 5-fluorouracil and leucovorin (modified FOLFOX-4 regimen) as first-line chemotherapy for elderly patients with advanced gastric cancer. Am J Clin Oncol. 2008;31:259-63.

16. Zhao JG, Qiu F, Xiong JP, Zhang L, Xiang XJ, Yu F, et al. A phase II study of modified FOLFOX as first-line chemotherapy in elderly patients with advanced gastric cancer. Anticancer Drugs. 2009;20:281-6.

17. Al-Batran S, Homann N, Hartmann JT, Moehler MH, Pauligk C, Probst S, et al. 5-fluorouracil, leucovorin, and oxaliplatin with or without docetaxel in elderly (65 years or older) patients with esophagogastric cancer: FLOT65 \pm trial of the Arbeitsgemeinschaft Internistische Onkologie (AIO). J Clin Oncol 2010;28(15 suppl): abstract 4013 .

18. Scott WK, Macera CA, Cornman CB, Sharpe PA. Functional health status as a predictor of mortality in men and women over 65. J Clin Epidemiol. 1997;50:291-6.

19. Santini D, Graziano F, Catalano V, Di Seri M, Testa E, Baldelli $\mathrm{AM}$, et al. Weekly oxaliplatin, 5-fluorouracil and folinic acid (OXALF) as first-line chemotherapy for elderly patients with advanced gastric cancer: results of a phase II trial. BMC Cancer. 2006;6:125.

20. Chau I, Ashley S, Cunningham D. Validation of the Royal Marsden hospital prognostic index in advanced esophagogastric cancer using individual patient data from the REAL 2 study. J Clin Oncol. 2009;27:e3-4.

21. Repetto L, Balducci L. A case for geriatric oncology. Lancet Oncol. 2002;3:289-97.

22. Lichtman SM, Wildiers H, Chatelut E, Steer C, Budman D, Morrison VA, et al. International society of geriatric oncology 
chemotherapy taskforce: evaluation of chemotherapy in older patients - an analysis of the medical literature. J Clin Oncol. 2007;25:1832-43.

23. Lewis JH, Kilgore ML, Goldman DP, Trimble EL, Kaplan R, Montello MJ, et al. Participation of patients 65 years of age or older in cancer clinical trials. J Clin Oncol. 2003;21: 1383-9.

24. Townsley CA, Selby R, Siu LL. Systematic review of barriers to the recruitment of older patients with cancer onto clinical trials. J Clin Oncol. 2005;23:3112-24.

25. Saif MW, Makrilia N, Zalonis A, Merikas M, Syrigos K. Gastric cancer in the elderly: an overview. Eur J Surg Oncol. 2010;36: 709-17.

26. Wagner AD, Unverzagt S, Grothe W, Kleber G, Grothey A, Haerting J, et al. Chemotherapy for advanced gastric cancer. Cochrane Database Syst Rev 2010;3:CD004064.
27. Trumper M, Ross PJ, Cunningham D, Norman AR, Hawkins R, Seymour M, et al. Efficacy and tolerability of chemotherapy in elderly patients with advanced oesophago-gastric cancer: a pooled analysis of three clinical trials. Eur J Cancer. 2006; 42:827-34

28. Cavanna L, Artioli F, Codignola C, Lazzaro A, Rizzi A, Gamboni A, et al. Oxaliplatin in combination with 5-fluorouracil (5-FU) and leucovorin $(\mathrm{LV})$ in patients with metastatic gastric cancer (MGC). Am J Clin Oncol. 2006;29:371-5.

29. Fonck M, Brunet R, Becouarn Y, Legoux JL, Dauba J, Cany L, et al. Evaluation of efficacy and safety of FOLFIRI for elderly patients with gastric cancer: a first-line phase II study. Clin Res Hepatol Gastroenterol. 2011;35:823-30. 